\title{
Climat - combattre le sentiment d'impuissance, vouloir des décisions
}

\section{Jean Martin}

Dr med., membre de la rédaction et ancien membre de la Commission nationale d'éthique

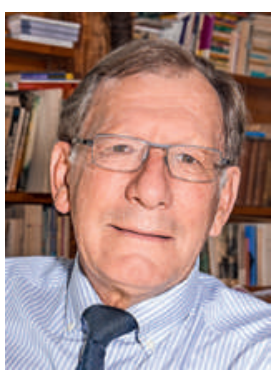

Martin J. Grands-parents pour le climat. Bull Méd Suisses. 2014;95(45):1714

2 Klein N. Tout peut changer-Capitalisme et changement climatique. Actes Sud/Lux; 2015. Urbinello D, Künzli N. Le changement climatique concerne aussi la santé. Bull Méd Suisses. 2015;96 (31/32):1087-8.
Le 30 novembre prochain commence à Paris la Conférence mondiale COP 21 sur le climat. L'espoir existe dans plusieurs milieux que des avancées majeures y seront enregistrées. D'autres restent désabusés par l'échec de Copenhague en 2009; toutefois, au plan politique comme sociétal, on voit des mouvements qui permettent d'espérer mieux. Dans la série Pardonnez-moi, sur RTS Un, Darius Rochebin interviewait le 16 août Nicolas Hulot, envoyé du Président Hollande pour la protection de la planète. Hulot a repris une formulation de Barack Obama, disant que nous sommes la première génération qui a conscience de sa vulnérabilité et la dernière qui a la faculté d'éviter que son destin lui échappe.

"Notre maison brûle et nous regardons ailleurs", avait dit Jacques Chirac au Sommet de la Terre de 2002 à Johannesburg. Personne n'aime les mauvaises nouvelles et c'est un facteur fort dans la difficulté à sensibiliser à la réalité des dangers, relevait Jacques Mirenowicz, rédacteur de LaRevueDurable, lors l'assemblée récente des «Grands-parents pour le climat» [1]. Il nous

La promotion des énergies renouvelables peut être un important facteur de paix.

coûte d'abandonner l'idée que la terre est corvéable à merci, que l'abondance est la norme... Aux Etats-Unis, la moitié du pays résiste bec et ongles à l'idée que l'homme est responsable des changements que nous subissons et dont, sauf réorientations capitales de nos modes de produire et de vivre, les effets seront catastrophiques (notion d'Anthropocène, à savoir que l'influence de l'activité humaine sur la planète a un poids "géologique»). Pourtant, note Hulot, les plus climato-conscients aux USA sont les militaires, peu suspects d'être des «greenies» (écologistes naïfs).

De vives pressions se marquent pour obtenir des décisions qui modifieraient dans le bon sens les pratiques actuelles, notamment: s'engager à laisser sous la terre (sans les exploiter) les 75-80\% des ressources non renouvelables qui y sont encore. Il s'agit, à la place, que «les énergies renouvelables deviennent une force économique révolutionnaire susceptible d'alimenter une transition socialement juste», dit la grande organisation 350.org active dans le monde entier (qui tire son nom du fait qu'il importe de redescendre vite du ni- veau actuel de 400 ppm de carbone dans l'atmosphère à 350). 350.org collabore avec la personnalité canadienne Naomi Klein [2].

Ensuite: désinvestir massivement, au plan financier, le domaine des énergies non renouvelables. Convaincu que le climat est l'enjeu principal du moment, le journal unanimement respecté The Guardian a décidé de militer pour cette cause. A fin juin, un groupe de leaders de la santé demandait dans le journal au Wellcome Trust, de s'engager dans un tel désinvestissement. Et le 14 août The Guardian publiait les noms de 1000 médecins et autres professionnels qui se sont associés à cet appel (dont des médecins suisses). Suite à l'encyclique Laudato si du Pape François, louée de tous côtés pour sa clarté et son importance politique, des appels sont lancés au Vatican aussi pour qu'il retire son argent du secteur non renouvelable.

Aujourd'hui, la pertinence des conclusions scientifiques du GIEC n'est plus contestée: les faits sont les faits - et, comme le disait un politique américain, si chacun a droit a son opinion, chacun n'a pas droit à ses propres faits! Et, au-delà du technique, est débattue de plus en plus une dimension autre, spirituelle, humaniste; les leaders religieux se réveillent. «L'humanité a rendez-vous avec elle-même; ce qui se joue à Paris, c'est l'irréversibilité des phénomènes", dit Hulot. Cela étant, la reddition devant la difficulté à changer (ou le paresseux «Cela a bien été jusqu'ici, cela ira bien encore quelque temps») ne sont pas des options acceptables. Notamment pour ceux dont le mandat est la sauvegarde de la santé - et le changement climatique a des impacts pathogènes considérables (la revue Lancet juge elle aussi que c'est une menace formidable [3]). Les médecins de plus, j'ai souvent dit ma conviction à cet égard, ont à jouer dans la société un rôle particulier de réflexion, de «sages». Au moment de la réunion de Paris comme à plus long terme, il importe que notre corporation apporte sa contribution en vue de résoudre une crise qui n'est pas seulement environnementale mais est, on le voit bien, une crise de civilisation.

Réfléchir encore à: les ressources non renouvelables ont très souvent au cours de l'histoire été des facteurs de guerres et d'oppression, la promotion des énergies renouvelables peut être un important facteur de paix. 